\title{
Momente des bürgerlichen Staates in der griechischen Polis (1)
}

\author{
Wolfgang Müller
}

Glaubst du, daß ein Staat, in dem die Urteile der Gerichte keinen Anspruch auf Gültigkeit erheben können, vielmehr von einzelnen Personen abgeändert und außer Kraft gesetzt werden können, weiterbestehen kann oder nicht vielmehr zugrunde gehen muß?

(Sokrates)

Die Überschrift fordert zum Widerspruch heraus, sie soll es wenigstens: Momente des bürgerlichen Staates in einer Sklavenhaltergesellschaft, in einer längst vergangenen, nichtkapitalistischen Gesellschaft? Gegen solchen Widerspruch geht die folgende Darstellung von der These aus, daß es eine ,antike bürgerliche Gesellschaft ${ }^{6}$ gegeben hat, die der ,modernen bürgerlichen Gesellschaft ' frappant ähnlich war, zumindest in deren frühen Phasen. Diese alte ,bürgerliche Gesellschaft' (der Begriff selbst stammt aus der athenischen Politikwissenschaft) war bestimmt von dem Konflikt zwischen herkömmlichen Formen direkter Vergesellschaftung (z. B. der Stammesorganisation) und einer bereits recht ausgedehnten Zirkulation von Waren bzw. der Existenz des Geldes. Diese allgemeinste Ware (als Münze, aber auch schon als Schatz und als Geld- und Handelskapital) ist nicht einfach das Instrument einer fortschrittlicheren Form der Güterverteilung und damit der Arbeitsteilung, sondern wesentlich der Ausdruck einer zukunftsträchtigen Weise der Vergesellschaftung, die im Verhältnis des Kapitals zur Lohnarbeit ganz zu sich selbst kommt. Daß schon im Geld als solchem eine neue Gestalt der Vergesellschaftung sich unheimlich ankündigt, wurde in der Antike empfunden und abwehrend ausgesprochen: „Jenes Schatzhaus, das sich jeder für sich mit Gold vollgefüllt hat, richtet diese GesellFachbereich Politische Wissenschaft an der Freien Universität Berlin gehalten habe. Bei der Bearbeitung wurde ich durch die Kritik von Wolfgang Kreutzberger, Wolf-Dieter Narr, Axel Schulte und Uwe Wesel unterstützt. 
schaftsform zugrunde", bemerkte Platon im "Staat" (S. 550 f) (2). Das Geld wurde also nicht nur als ein nützliches Ding oder Instrument zur Erleichterung des Austauschs begriffen (auch diese Auffassung wurde aber schon formuliert), sondern als eine neue, rücksichtslos-dynamische und über die Köpfe der Menschen verselbständigte Macht, als Got theit wahrgenommen (3).

Aber nicht nur die gegenüber dem Lebensprozeß der Menschen verselbständigte Form des Geldes ist in jener vorkapitalistischen Gesellschaft der griechischen Polis schon ausgebildet: auch einzelne, und vielleicht wesentliche Momente des bürgerlichen Staates sind in der griechischen, und deutlicher noch in der römischen Antike vorgebildet. Diese These soll im folgenden an ausgewählten Punkten belegt werden. Diese Belege werden den Hauptteil des vorliegenden Aufsatzes bilden; nur kursorisch sollen einige der einleitenden Bemerkungen aufgenommen werden. Diese Vorgehensweise ist eine implizite Kritik an bestimmten Tendenzen in der in den letzten Jahren erneuerten marxistischen Staatsdiskussion (aus dieser Diskussion ist die Fragestellung dieses Aufsatzes entstanden). Wenn das ,innere Band ${ }^{6}$ der geschichtlichen Entwicklung aufgesucht werden soll, so ist dies nicht ohne die eigenständige Aneignung des historischen Materials möglich, und zwar dieses Materials in der höchst detaillierten und ,ideologischen' Gestalt, in der es jeweils vorliegt, wie immer, verkehrt ${ }^{6}$ oder zusammenhangslos diese sein mag. In manchen Erörterungen über die Methode der Darstellung, der Aufeinanderfolge der Kategorien, der Reproduktion der Wirklichkeit im Denken gewinnt man den Eindruck, daß diese Wirklichkeit in all den vielfältigen, ja chaotischen Details, in denen sie nun einmal in unser Bewußtsein tritt, gar nicht mehr ernstlich zur Kenntnis genommen wird, daß die ,Ableitung' zum bequemen Schlüssel geraten ist, mit dem man rasch die ,Welt der Erscheinungen' ordnen kann; ein Verfahren, das ein wenig an positivistische Theo-

2 Vgl. auch die Verse von Sophokles, Antigone 295 ff.:

Denn unter allem, was in Brauch ist unter den Menschen,

Erwuchs so schlimm nichts wie das Geld! Dieses zerstört

Selbst Städte, dieses treibt Männer von den Häusern,

Dies lehrt und es verkehrt den rechten Sinn

Der Menschen, üblem Tun sich zuzuwenden.

Wie man zu allem fähig wird, zeigt es den Menschen

Und jede Art Gottlosigkeit zu wissen.

Man sah also nur die zersetzende Seite, die Zerstörung der alten Ordnung, und konnte auch schwer etwas anderes sehen, denn die Entfaltung der produktiven Kräfte der menschlichen Arbeit war nur ganz peripher von dem Vermehrungsdrang des Geldkapitals in Gang gesetzt worden. (Die Bereicherung als Selbstzweck, der endlose Prozeß der Wertvermehrung ist jedenfalls schon mit dem Geld in seiner dritten Formbestimmtheit eingefuhrt, und nicht erst mit dem Kapital im Verhältnis zur Lohnarbeit. Dieser für das Verständnis der antiken Gesellschaft beachtenswerte Punkt wird vielfach übersehen, wahrscheinlich weil der Übergang vom Geld in seiner dritten Bestimmung zum Kapital von Marx im ,Kapital ${ }^{\star}$ wenig befriedigend entwickelt ist; man vergleiche dagegen die einschlägigen Abschnitte in den ,Grundrissen'.)

$3 \mathrm{VgL}$ insgesamt zu der hier vorgetragenen These meine Untersuchung zur Genesis der Formen abstrakter Identität aus der Entwicklung der Warentauschbeziehung, die voraussichtlich in diesem Jahr erscheinen wird (hier insbesondere Teil I). 
riebildung, stärker an ontologische Theorien erinnert. Ohne gründliche Abarbeitung an der vergangenen und der gegenwärtigen gesellschaftlichen Entwicklung in ihren verschiedenen Einzelheiten ist jeder Versuch einer ,Rekonstruktion der marxistischen Theorie ${ }^{6}$ in der Gefahr, zur bloßen Deduktion aus Ersten Prinzipien oder zum kritiklosen Nachvollzug fertiger ,Systeme ${ }^{6}$ zu verkommen (4). Es ist keineswegs möglich, diese Auseinandersetzung mit der vergangenen und der bestehenden Wirklichkeit bzw. ihren theoretischen Verarbeitungsformen aufzuschieben bis zur Vollendung der Phase der Rekonstruktion. Nur wo die theoretische Anstrengung sich aus dem Versuch eines reflektierten und praktisch interessierten Begreifens der gegenwärtigen gesellschaftlichen Bewegung ergibt und auf diese Bewegung in allen ihren Problemen und Ungereimtheiten bezogen bleibt, kann Theorie der Gefahr entgehen, sich in sich selbst zu bewegen. Gerade die marxistische Staatsdiskussion der letzten Jahre ist ohne Kenntnis ihrer praktischen Anstöße (z. B. der Frage nach dem Verhältnis von Politik und Ökonomie im Faschismus und der Wendung zur ,Formierten Gesellschaft') als politische Diskussion nicht zu verstehen (5). Unter Verzicht auf eine ,ableitende" oder ,methodologische" Einleitung soll daher sogleich zur Fragestellung dieses Aufsatzes übergegangen werden.

Gehen wir von allgemein verbreiteten Kenntnissen aus: eine Reihe auch heute noch normaler staatlicher Funktionen wie auch anderer Formen der modernen bürgerlichen Gesellschaft finden sich bereits in der griechischen und römischen Antike. Jeder erinnert sich z. B. an die Weihnachtsgeschichte, „daß ein Gebot vom Kaiser Augustus ausging, daß alle Welt geschätzt würde" (Evangelium des Lukas, 2,1 ). Von der römischen Reichsverwaltung sollte also eine Volkszählung veranstaltet werden, die die amtliche Grundlage für eine geordnete und einheitliche Besteuerung abgeben sollte. Daß damals Handelsbeziehungen und Münzgeld verbreitet waren, geht ebenfalls aus dem Neuen Testament hervor, ebenso, daß der Apostel Paulus römischer Bürger war und daher eine quasi rechtsstaatliche Behandlung genoß (im Unterschied von anderen Schichten der Reichsbevölkerung). Das römische Recht war schließlich so hoch entwickelt, daß es noch heute Struktur und Begrifflichkeit unseres Bürgerlichen Gesetzbuches bestimmt; es hat sich in der Entstehungszeit der modernen bürgerlichen Gesellschaft als ein nützliches Instrument erwiesen, um die Verselbständigung einer , absoluten', außerökonomischen Staatsgewalt voranzutreiben, und es war selbst Ausdruck und Instrument einer hochentwickelten und hochzentralisierten Staatsmacht, die wenigstens für einige Jahrhun-

Vg1. dazu Blanke/Kastendiek/Jürgens (Zur neueren marxistischen Diskussion über die Analyse von Form und Funktion des bürgerlichen Staates. Überlegungen zum Verhältnis von Politik und Ökonomie. In dieser Zeitschrift, Heft 14/15); sie weisen an verschiedenen Stellen auf ein quasi ontologisches Denken in der marxistischen Staatsdiskussion hin. Dabei wird von einem ,Wesen“",des Staates" ausgegangen, das schon alle seine Funk tionen enthalten soll - die erscheinende Wirklichkeit kann dann entweder deduziert (,abgeleitet ${ }^{5}$ ) werden, oder sie wird als bloße Zufälligkeit an den Rand gedrängt (vgl. S. 62 f., $101 \mathrm{f}$. u. ö.). Die Aufgabe der konkreten Vermittlung zwischen Empirie und allgemeinem Begriff existiert für ein solchę Denken nicht mehr.

$5 \quad \mathrm{Vgl}$ die Erinnerung daran bei Blanke/Kastendiek/Jürgens, S. 58-60. 
derte ein ,Welthandelsreich" in den Randgebieten des Mittelmeers ermöglichte. Die Ausdehnung von Warenaustausch bzw. Geldverhältnissen läuft historisch anscheinend der Herausbildung eines ,Rechtsstaatss oder einer ,außerökonomischen Zwangsgewalt ${ }^{\circ}$ parallel (6) - und zwar vor Herausbildung des kapitalistischen Produktionsverhältnisses, bei allerdings erheblicher Entwicklung des Warenverkehrs. Die hier zu erörternde These ist deshalb: Momente der entwickelten bürgerlichen Gesellschaft und daher auch des bürgerlichen Staates finden sich schon in der antiken bürgerlichen Gesellschaft. (Ob damit der Staat des Imperium Romanum oder der griechischen Polis wesentlich bestimmt ist, wird ebenfalls zu fragen sein).

Um diese These nicht ganz allgemein, sondern direkt auf das historische Material und das heißt auf den heutigen Forschungsstand bezogen zu erörtern, soll nur ein kleiner, doch einigermaßen relevanter Abschnitt der antiken Entwicklung, und hier nur der griechischen Geschichte betrachtet werden. Vor allem das der klassischen Epoche der griechischen Polis vorausgehende 6. Jahrhundert, gelegentlich auch noch das 7. sowie das 5. und 4. Jahrhundert werden in diesem Aufsatz im Mittelpunkt stehen, und innerhalb dieser zeitlichen Einschränkung hauptsächlich die Polis Athen. Dafür spricht vor allem die Quellenlage, die für Athen vergleichsweise günstig ist - keineswegs zufällig, denn als frühe und exemplarische Form bürge rlicher Zivilisation hat Athen auch eine reiche und differenzierte Schriftkultur hervorgebracht, von der wichtige Bruchstücke erhalten sind. Allerdings im wesentlichen seit dem 5. Jahrhundert; für die archaische Zeit stellt sich die historische Forschung daher als ein Puzzlespiel dar, bei dem 9 von 10 Stücken fehlen und durch quellenkritische Rückschlüsse erschlossen werden müssen. Entsprechend zahlreich sind die Kontroversen und offenen Fragen, auf die auch hier aber höchstens am Rande eingegangen werden kann.

Zunächst soll ein knapper Überblick über den Entwicklungsstand der materiellen Produktion und ihrer Form in der athenischen Polis hauptsächlich des

6 Rechtsstaat ist hier eine Formel, mit der bestimmte Formprinzipien, nicht aber inhaitliche Probleme bezeichnet werden sollen (wie sie etwa in der deutschen staatsrechtlichen Tradition unter den Begriffen des materiellen, formellen oder sozialen Rechtsstaates behandelt worden sind).

Außerökonomische Zwangsgewalt ist ein von Blanke/Kastendiek/Jürgens (S. 68 f.) eingeführter Begriff, mit dem die rechtsetzende und rechtdurchsetzende Funktion des bürgerlichen Staates noch unabhängig von sonstigen Funktionen und der historischen Erscheinungsweise bezeichnet und als Elementarfunktion begrifflich - aus der Warenform abgeleitet - vor anderen Funktionen herausgehoben wird. In dem besonderen Interesse für diese ,Grundfunktion" bin ich mit Blanke/Kastendiek/Jürgens einig (und übrigens auch mit Dieter Läpple in seiner Untersuchung Staat und allgemeine Produktionsbedingungen. Grundlagen zur Kritik der Infrastruk turtheorien, Westberlin 1973, insbes. S. 36-46). Im Zusammenhang mit diesen Überlegungen ist auch wieder die Bedeutung der Arbeit von E. Paschukanis in Erinnerung gerufen worden (Allgemeine Rechtslehre und Marxismus, deutsch Wien und Berlin 1929, Neudruck im Verlag Neue Kritik, Frankfurt/M. 1966). Auf das historische Problem der „Parallelität der Herausbildung des Geldverhältnisses und einer separaten außerökonomischen Zwangsgewalt" gehen Blanke/Kastendiek/Jürgens nur im Vorübergehen ein (S. 70), und zwar nur im Zusammenhang der direkten Vorgeschichte der kapitalistischen Gesellschaft. 
6. Jahrhunderts gegeben werden. Dabei wird bereits ein wichtiges Moment moderner Staatstätigkeit sichtbar werden, die einheitliche Regelung von Maßen, Gewichten und Münzen. Nur eine andere Seite davon und besonders für die Konstitution der Form der bürgerlichen Person wesentliches Moment ist die Herausbildung eines staatlichen Gerichtszwangs bzw. die Zurückdrängung von Selbsthilfe, Blutrache usw. Diese Herausbildung einer Frühform des Rechtsstaats ist gleichbedeutend mit der Emanzipation der Rechtsperson aus den Bindungen der Gentilverbände, bzw. der Anerkennung der Freiheit, über sich selbst, über das eigene Handeln und das private Eigentum zu verfügen. Daß dies - im Verhältnis zur modernen bürgerlichen Gesellschaft - nur beschränkte Anfänge sind, wird sich dann bei einer genaueren Untersuchung von Kategorien wie Eigentum und Vertrag zeigen, die selbst in den späteren Jahrhunderten nicht das Niveau des entwickelten römischen Rechts erreicht haben. Dabei ist noch von der bekannten Tatsache abgesehen, daß in Athen ein erheblicher Teil der Bevölkerung, vor allem die Sklaven, nicht den Status bürgerlicher Rechtsfähigkeit besaß. Nach dieser Relativierung einzelner Kategorien des bürgerlichen Rechts wird auch grundsätzlich die Ausgangsthese erörtert werden, indem schließlich nach dem wesentlichen Charakter des athenischen Staates gefragt wird. Vor allem wird hier zu fragen sein, ob man bereits von einer Verselbständigung dieses Staates gegenüber der Gesellschaft sprechen kann, ob daher überhaupt der Begriff des Staates am Platze ist.

Zunächst zum Entwicklungsstand der materiellen Produktion. Die große Masse der gesellschaftlichen Arbeit wurde in Athen im 6. Jahrhundert (und prinzipiell auch noch in den folgenden Jahrhunderten) für die Selbstversorgung in der landund hauswirtschaftlichen Produktion verausgabt, vielfach, wenn damals auch sicher noch nicht überwiegend, als unfreie Arbeit. Nur ein geringer, allerdings schnell steigender Teil der Produkte ging in den Austausch ein (der wegen des technischen Entwicklungsstands der Transportmittel in der Antike vorherrschend Seehandel war). Vieles davon verdient freilich den Namen Handel noch nicht; erst recht sind Vorstellungen einer sich durchsetzenden ,Industrie“ oder gar ,fabrikmäßigen Industrie"(7) auch für Athen durchaus fehl am Platz, obwohl solche Begriffe in der Literatur immer noch sehr verbreitet sind. Immerhin muß die Herstellung von keramischer Exportware in Handwerksbetrieben jedenfalls in der 2. Hälfte des 6. Jahrhunderts stark zugenommen haben, wie die Funde in der Agäis und in Süditalien

$7 \mathrm{Vgl}$ als Beispiel für eine ,modernisierende' Interpretation Busolt/Swoboda: ,Die beschränkte und unvollkommene Rechtspflege genügte nicht mehr den Bedürfnissen der neueren Zeit, die im 7. Jahrhundert anbrach. In Verbindung mit der großen Kolonialbewegung vollzog sich die Entwicklung von Großhandel und fabrikmäßsiger Industrie, der Übergang der Naturalwirtschaft zur Geldwirtschaft. Neben den alten Hauptelementen der freien Bevölkerung, dem grundbesitzenden Blutsadel, den Bauern und Ackerbürgern, erwuchs in den Handels- und Industrieplätzen ein zahlreiches städtisches Bürgertum". (G. Busolt/H. Swoboda, Griechische Staatskunde. 2 Bände (im Handbuch der Altertumswissenschaft, IV. Abt, I. Teil), München 1920, 1926, hier Bd. I, S. 520). Als umfassende Sammlung der ,Staatsaltertümer" ist dieses Werk immer noch unentbehrlich, während die Verarbeitung des Materials wenig eigenständig ist.) 
zeigen. In diesen Töpfererzeugnissen wurden attisches Olivenöl und Wein exportiert; Importwaren waren vor allem Getreide, Metalle (außer Silber), auch wohl schon Sklaven. In der Landwirtschaft entwickelt sich bereits eine über den Warenaustausch vermittelte Arbeitsteilung (Ölbäume statt Getreide). Athen war also spätestens in der 2. Hälfte des 6. Jahrhunderts ein Handelszentrum (nicht eine ausschließlich vom Handel lebende Handelsstadt), das die etwas älteren Handelszentren am Saronischen Golf (Aigina, Korinth) zu überflügeln begann. Ein rasch zunehmender (insgesamt aber doch recht kleiner) Teil der landwirtschaftlichen und vor allem der gewerblichen Produktion war für den Export bestimmt. In diesen Jahrzehnten war Athen der Schauplatz eines neuartigen und in vieler Hinsicht zukunftsweisenden Umschwungs in der Art und Weise der gesellschaftlichen Lebenserhaltung. Andere Gemeinwesen verharrten in den alten Formen; Sparta wurde später bewußt als Gegenbild der ,alten Ordnung ${ }^{6}$ herausgehoben. Mit Blick auf die in Athen sichtbar gewordenen umwälzenden Folgen war hier das Geld auf seine Funktionen als Maßstab der Preise und als Zirkulationsmittel beschränkt worden, indem nur Eisenmünzen zugelassen wurden.

Ein besonders eindrucksvolles Indiz für den Umschwung im 6. Jahrhundert bietet die Geschichte der Münzen (der Übergang zur Münzform bezeichnet den Einschnitt, an dem das Geld auch in seiner äußeren Gestalt sich von allen übrigen Waren abhebt). Nach der Prägung der ersten Münzen aus Elektron in Städten an der kleinasiatischen Küste gegen Ende des 7. Jahrhunderts finden sich die ersten Münzen aus Silber in Aigina, der Nachbar- und Konkurrenzstadt Athens. Man kann davon ausgehen, daß diese Münzen auch in Athen umgelaufen sind. Eigene Münzen prägt Athen erst gegen Mitte des 6. Jahrhunderts; erhebliche Verbreitung findet das athenische Geld erst in der zweiten Jahrhunderthälfte. Schon um 520 beginnt in Athen die Prägung jener berühmten, ,Eulen' genannten Silbermünzen, die die anderen Währungen bald aus dem Fernhandel zurückdrängten und für Jahrhunderte die Rolle eines Weltgeldes des Mittelmeergebietes spielen sollten. Bereits vorher hatte auch die Prägung von kleineren Denominationen begonnen, die allmählich immer mehr unterteilt wurden und die für die Verwendung des Münzgeldes im alltäglichen Detailhandel Voraussetzung sind, wie er für das 5.Jahrhundert auch literarisch bezeugt ist. Gerade für diese Kleinmünzen war der Schritt zur Silberprägung notwendig; materielle Bedingung waren die reichen attischen Silbervorkommen. Neben dem durch Münzgeld vermittelten Austausch hat aber sicher immer auch unmittelbarer Tauschhandel stattgefunden.

Die Eulen-Selbermünzen werden von der heutigen Geschichtsschreibung als bewußter und erfolgreicher Versuch der athenischen Tyrannen verstanden, der eigenen Währung die Rolle des allgemeinen Aquivalents im Fernhandel zu verschaffen. Ihre äußere Gestalt weist selbst deutlich genug auf die sie garantierende zentrale Macht hin, die sich gegen rivalisierende Adelsgeschlechter durchgesetzt hat. Denn waren die vorausgehenden Silbermünzen mit den verschiedenen Wappen dieser Geschlechter geprägt worden, so haben die Eulenmünzen schon die bis heute übliche Gestalt von Münzen: das Profil der Stadtgöttin und, Landesmutter ${ }^{6}$ Athene 
auf der Vorseite, die ihr heilige Eule als Wappentier zusammen mit den Initialen ATHE auf der Rückseite (8). Wir haben hier gewissermaßen den handgreiflichen Anhaltspunkt für alle Geldtheorien, die das Geld als durch Übereinkunft bzw. durch staatliche Setzung begründet begreifen (sie sind übrigens selbst zuerst in Athen formuliert worden und haben über das römische Recht den absolutistisch-merkantilistischen Staat erreicht)(9). An die markantilistische Gewerbeförderung erinnert übrigens auch die Förderung von Handel und Gewerbe durch große Aufträge für öffentliche Bauwerke und durch Straßenbauten, sowie eine Wasserleitung, die durch die Tyrannen von Athen errichtet wurde; wir können diesen Punkt hier nur erwähnen. (Diese Hinweise auf die Rolle, progressiver Fürsten in der älteren Geschichte Athens bedürften der Ausführung: es wäre im einzelnen zu zeigen, in welchen Hauptschritten, gegen welche Hindernisse, durch welche entscheidenden Konflikte und über welche Hauptakteure sich die neuen Tendenzen durchsetzten. Warum z. B. setzen sie sich in Athen durch, in Sparta nicht? Warum wurden die Hauptakteure dieser Entwicklung, die Tyrannen, gegen Ende des 6. Jahrhunderts durch eine zur Demokratie aller freien Athener tendierende Verfassung ersetzt? Welche Knotenpunkte dieser Entwicklung wären zu bezeichnen? Diese Aufgabe eigentlicher, auch die politische Entwicklung im einzelnen nachzeichnender Geschichtsschreibung ist hier nicht zu leisten, nicht zuletzt, weil die schriftliche Überlieferung für diese Zeit noch sehr dürftig ist und viele Resultate der Forschung stark hypothetischen Charakter haben. Ohne Rekurs auf die Mittel verschiedener Fachwissenschaften bzw. die Interpretation sprachlicher und archäologischer Überlieferung ist sie ohnehin nicht zu bewältigen. In diesem Śinn kann es sich im folgenden nur um Andeutungen auf den Gang der Geschichte handeln.)

Wenn die Tyrannen, nicht nur in Athen, eine wichtige, ,progressive 6 Rolle gespielt haben, so blieben sie doch eine Episode von wenigen Jahrzenten. Schon vor ihnen tritt der berühmte Solon auf, der sonderbevollmächtigte Jahresbeamte des Jahres 594/93 und nach Auffassung vieler Autoren ,der erste Staatsmann der europäischen Geschichte'. Diesen Titel hat man ihm vor allem wegen seiner Tätigkeit als Schlichter der Klassenkämpfe zwischen Großgrundbesitzern und verschuldeten, ja teilweise versklavten Kleinbauern verliehen. Indem er die Kleinbauern durch einen allgemeinen Schuldenerlaß befreite, legte er eine wichtige Basis für die Ausdehnung von Handel und Gewerbe und sicherte zugleich die Grundherren vor einer radikalen Landaufteilung bzw. offenem Bürgerkrieg. In unserem Zusammenhang interessiert besonders die dem Solon zugeschriebene Reform von Maß, Gewicht und Münze.

8 Vgl. C. M. Kraay, The Archaic Owls of Athens. Classification and Chronology. In: Numismatic Chronicle. 6th Series, Bd. 16 (1956) S. 43-68.

9 Die beiden einflußreichsten Stellungnahmen antiker Autoren, in denen das Geld - nämlich in seinen Bestimmungen als Maßstab der Preise und als Zirkulationsmittel - als ein nützliehes Mittel aufgefaßst ist, das zur Überwindung der beim unmittelbaren Produktenaustausch auftretenden Schwierigkeiten durch Übercinkunft eingeführt worden ist, sind von Aristoteles und dem römischen Juristen Paulus (Nikomachische Ethik V, 5, S. 1133 a 25 ff.; Digesten, XVIII, 1.) 
Person in Griechenland und vor allem in Athen in der Epoche zwischen dem 7. und dem 4. Jahrhundert herausgearbeitet worden; das späte 7. und das 6. Jahrhundert ragt nicht zu Unrecht durch die Namen der großen Gesetzgeber Drakon, Solon und Kleisthenes heraus. Im folgenden soll zunächst das Neuartige und Vorwärtsweisende dieser Entwicklung skizziert werden; danach wird es darauf ankommen, ihre charakteristische Beschränktheit selbst im Fortgang der späteren Jahrhunderte einzudeuten.

Wenn hier die Freiheit der Person und damit überhaupt die Kategorie der Person als charakteristisch Neuartiges hervorgehoben wird, so muß gleich hinzugesetzt werden, daß damit nur ein Moment einer umfassenden Entwicklung benannt worden ist. Mit nicht geringerem Recht könnte man auch Kategorien wie den freien Willen und die Gleichheit des Individuums bzw. der Rechtsperson, weiter auch Begriffe wie Eigentum und Vertrag, Haftung, Schuld und Strafe, Gesetz und Rechtsprechung, schließlich vor allem Souveränität und Staat als Faden der Entwicklung herausheben. Selbst die Herausbildung der reinen Erkenntnisbeziehung, der uns so selbstverständlichen Fähigkeit zur abstrakten Rationalität des mit anderen in dieser Beziehung identischen Erkenntnissubjekts, bzw. auch die Entstehung einer Welt identischer und in ihren Beziehungen durch Gesetze bestimmbarer Objekte wäre als ein Moment dieser umfassenden Entwicklung zu nennen (12). Wie sehr dies alles für den Lebensprozeß einer über Tauschbeziehungen verknüpften Gesellschaft notwendig ist, kann man sich ohne lange Ausführungen am ehesten klar machen, wenn man den Lebensproduktionsvorgang vorkapitalistischer Gesellschaften studiert, wo alle diese Existenz- und Bewußtseinsformen wenig oder gar nicht entwickelt sind (13). $\mathrm{Daß}$ die Etablierung kapitalistischer Verhältnisse ganz entscheidend von der Begründung solcher Formen des sog. Überbaus vorangetrieben wird, das wird auch an der Bedeutung der puritanischen Fassungen des Christentums für Europa und an der Rolle der christlichen Mission bei der Erzeugung bürgerlicher Individuen aus ,Eingeborenen ${ }^{6}$ deutlich. Alle genannten, uns selbstverständlichen Kategorien und Institu. tionen, Rechtsperson, Gesetz, Strafe usw., haben sich in jener Epoche zuerst entwickelt, die als Epoche der ,antiken bürgerlichen Gesellschaft ${ }^{\circ}$ jene frappante Ähnlichkeit mit der modernen bürgerlichen Gesellschaft zeigt. Und alle diese Begriffe sind auch geeignet, die Beschränktheit dieser Vorform der modernen Gesellschaft zu zeigen.

Im folgenden soll zunächst die Entwicklung von der Selbsthilfe der Gruppe gegen Unrechtstäter (z. B. der Blutrache) bis zur Herstellung einer öffentlichen Gerichtshoheit bei einer erheblichen Zahl von Delikten im 6. Jahrhundert darge-

12 Vgl dazu die oben, Anmerkung 3, angegebene Untersuchung.

13 Es gilt dies also keineswegs bloß für die frühgriechische Gesellschaft (wo es sich z. B. am homerischen Epos zeigen läßt), sondern auch für zeitgenössische, aber ungleichzeitige Gesellschaften. Vgl etwa für die vietnamesische Gesellschaft: $E$. Wulff, Grundfragen transkultureller Psychiatrie. In: Das Argument, Nr. 50 (1969), S. 227-60 (jetzt auch, zusammen mit teilweise detaillierteren Berichten, in: ders., Psychiatrie und Klassengesellschaft, Frankfurt/M. 1972); für zwei nordamerikanische Ind ianer stämme: Erik H. Erikson, Kindheit und Gesellschaft (1950), deutsch Stuttgart 1965, Zweiter Teil. 
Während seine Rolle bei der Münzreform neuerdings vorwiegend als Retrojektion des 4. Jahrhunderts verstanden wird, bezweifelt man nicht, daß er Gewicht- und Maßsystem neu geregelt hat, und zwar mit der Absicht, Athen an ein für den Handel aussichtsreicheres System anzuschließen und die Abhängigkeit vom System der Konkurrenz (Aigina) zu beseitigen. Während die Forschung sich aber in größter Ausführlichkeit mit der Interpretation der Überlieferung der solonischen Reformen beschäftigt, (10) wird die Tatsache der einheitlichen Regelung der Maße selbst kaum grundsätzlich gewürdigt, geschweige denn interpretiert. Es wird nicht gesehen, daß eine derartige Regelung überhaupt nur in einem gesellschaftlichen Entwicklungsstand notwendig und sinnvoll sein kann, wo die unmittelbare, autoritative Verteilung der Produkte z. B. gemäß den Stammestraditionen nicht mehr allein herrscht, sondern wo ein Teil der Produkte regelmäßig in den Austausch eingeht, d. h. in bestimmten Gebrachswertquanten irgendwie gleichgesetzt werden muß. Es wird vor allem nicht das Problem gesehen, das in dieser Gleichsetzung des Ungleichartigen steckt, von der doch schon Aristoteles konstatierte, sie sei , in Wahrheit unmöglich" (11); einer ohne Bewußtsein vollzogenen Abstraktion, die erst in der bis zur Gewaltsamkeit gleichgültigen Quantifizierung, Bewertung, ja Entwertung der konkreten Arbeitsfähigkeiten der Lohnarbeiter durchs Kapital ihre volle Höhe erreicht.

Halten wir einstweilen fest: die Entwicklung des Warenaustauschs war in Athen am Anfang des 6. Jahrhunderts ausgedehnt genug, um eine einheitliche Regelung der Warenmaße und Warengewichte durch eine über die einzelnen Gruppen und Individuen der Gesellschaft erhobene zentrale Autorität zu erfordern; gegen Ende desselben Jahrhunderts war Athen als Handelszentrum entwickelt genug, um einer eigenen, vom Staat einheitlich geregelten und garantierten Münze und Münzordnung zu bedüfen. Warum sich dieses ,Erfordernis" durchsetzen konnte, warum überhaupt ein solches ,Bedürfnis" auftrat, ist damit allerdings noch nicht gezeigt, eine von wirklicher Geschichtsschreibung zu schließende Lücke. Der Hinweis auf eine ,allgemeine Notwendigkeit ${ }^{\natural}$ genügt beim Geld sowenig wie beim Kapital, wenn nicht eine funktionalistische Deduktion die Darstellung der geschichtlichen Entwicklung und aller ihrer Komplikationen und Widersprüchlichkeiten ersetzen soll.

Eine entscheidenede Bedingung für die Ausdehnung regelmäßsiger Warentauschbeziehungen ist die Anerkennung der Freiheit der Person, zumindest in der Gestalt, daß die persönliche Unversehrtheit an Leib und Leben auch beim Aufenthalt außerhalb des unmittelbaren Machtbereichs der eigenen Haus- und Dorfgemeinschaft oder der Sippe gesichert ist (vgl. die allmähliche Durchsetzung des Landfriedens seit dem hohen Mittelalter). In bestimmter Weise ist Realität und Begriff der

10 VgL neuerdings die ausführliche und auch zur Einführung in die ältere Literatur geeignete Untersuchung von M.R. Cataudella, Atene fra il VII e il VI secolo. Aspetti economici e sociale dell'Attica Arcaica. Catania 1966 (Università di Catania. Pubblicazioni della Facoltà di Lettere e Filosofia, Bd. 23).

11 Aristoteles, Nikomachische Ethik, Buch V, 5, S. 1133 b 19. Vgl. dazu K. Marx, Das Kapital, Bd. 1, MEW Bd. 23, S. 73 f. 
stellt werden (14). Schon der Begriff ,Unrechtstäter ${ }^{6}$ ist für die sogenannte vorgeschichtliche Zeit (d. h. die Zeit vor dem Gebrauch der Schrift) fehl am Platz; noch Odysseus kann das Inkognito des vor der Blutrache fliehenden ,Mörders wählen, ohne deswegen irgendeine Verfolgung oder Diskriminierung befürchten zu müssen, solange er sich außerhalb der Reichweite der betroffenen Gruppe aufhält. Und zwar tritt nur die Gruppe dem Verletzten zur Seite, die überhaupt für seine gesamte Existenz die Grundlage ist; also vor allem die patriarchalische Großfamilie oder Hausgemeinschaft (Oikos), daneben auch der kleinbäuerliche Verband der Nach. barn oder die kriegerisch-aristokratische Vereinigung der Kameraden (letztere beiden Gruppen ein Hinweis auf klassenspezifische Verbindungen). Die Rache kennt, im Unterschied zur Strafe, keinerlei allgemeine Schranken; ihr einziger Maßstab ist das Ehrgefühl der Betroffenen. Daher kann sie mit deren Einverständnis auch bei Mord durch eine Buße (,Wergeld') abgelöst werden. Eine wichtige Einschränkung der Selbsthilfe liegt bereits in der erst freiwilligen, dann obligatorischen Anerkennung eines Schiedsspruchs, die Aufschub und möglicherweise eine Modifikation der Selbsthilfe bedingt. Der obligatorische Schiedsspruch ist ohne ein Minimum zentralisierter Autorität nicht möglich, die allerdings zunächst nicht mehr sein mag als die Versammlung der Gemeinfreien oder der Adeligen.

Eine „Art der Souveränität" (15) wird deutlicher, sobald der Schiedsspruch sich auf anerkannte und bekannte ,Gesetze stützt, in denen die Tatbestände benannt und die Bußen fixiert sind. Ein für das griechische Geschichtsbewußtsein entscheidender Schritt liegt in der schriftlichen und öffentlichen Fixierung solcher Gesetze und in der Anerkennung der Gleichheit aller Vollbürger vor diesen Gesetzen. Damit ist die Stufe der Kodifikationsbewegung des 7. Jahrhunderts erreicht, die in Athen mit den Namen Drakons und Solons bezeichnet ist und mit der die Geschichte des Rechtes und damit auch des Staates in dem uns vertrauten Sinne beginnt. (Wenn einzelne ,Gesetzgeber" genannt werden, so ist davon auszugehen, daß sie im allgemeinen nur den erreichten Stand der Rechtsauffassung kodifiziert, nicht etwa neues Recht geschaffen haben.)

Die älteste Überlieferung ist das Blutrecht des Drakon (gegen Ende des 7. Jahrhunderts). Nur nach gerichtlicher Klärung von Tatbestand und Willensrichtung des Totschlägers wird hier gegebenenfalls die Selbsthilfe zugelassen; es herrscht

14 Zum folgenden vgl. besonders: $K$. Lotte, Beiträge zum griechischen Strafrecht. In: Hermes, Bd. 66 (1931), S. 30-48, 129-158 (auch in: ders., Kleine Schriften, München 1968, S. 252 ff.); ders, Der Rechtsgedanke im archaischen Griechentum. In: Antike und Abendland, Bd. 2 (1946), S. 63-76 (auch in: ders., Kl. Schriften, S. 233 ff.); $R . J$. Bonner, G. Smith, The Administration of Justice from Homer to Aristotle. Chicage 1930 , Bd. 1; J. W. Jones, The Law and Legal Theory of the Greeks. An Introduction. Oxford 1956.

15 Vglo L. Gernet, Sur la notion du jugement en droit grec. In: ders. Droit et société dans la Grèce ancienne. Paris 1955, S. 61-81; hicr zitiert nach der dcutschen Übersetzung: Über den Begriff des Urteils im griechischen Recht. In: Zur griechischen Rechtsgeschichte. Hrsg. E. Berneker. Darmstadt 1968, S. 374-412, hier S. 382. „Wir erinnern dabei nur an die Wendungen von Aristoteles, für den das dikázein ein notwendiges Element der ,politjschen" Macht ist..." (ebd.). 
also Gerichtszwang. Während in älterer Zeit nur das Resultat, der Tote, zählte (mit allen Begleiterscheinungen fortdauernder Blutrache, wie sie noch heute etwa aus Teilen Jugoslawiens bekannt sind), wird im drokontischen Gesetz die fundamentale Unterscheidung zwischen Mord und Totschlag einerseits und fahrlässiger Tötung andrerseits getroffen (nach unseren heutigen Begriffen, vgl. Strafgesetzbuch $\S 211 \mathrm{f}$. und 222). Erkennt das Gericht auf vorsätzliche Tötung, so wird der Täter dem sofortigen Zugriff der Verwandten des Getöteten ausgeliefert. Wird auf unvorsätzliche Tötung erkannt, so wird zwar auch das Recht auf Selbsthilfe bestätigt, jedoch mit der Maßgabe, daß der Verurteilte freien Abzug ins Ausland erhält und daß sein Eigentum nicht für Repressalien freigegeben wird. Außerdem kann auf bußlose Tötung erkannt werden, z. B. bei Gegenwehr gegen Raub; die Angehörigen verlieren dann ihren Anspruch auf Rache. Das für die weitere Entwicklung entscheidend Wichtige ist die im Begriff des Vorsatzes enthaltene prinzipielle Anerkennung der Freiheit des Willens, der Autonomie und daher Verantwortlichkeit des Einzelnen bei der Tat. Die Anerkennung dieser Autonomie des Individuums bedarf allgemeiner, über den einzelnen Sippenverbänden und dergleichen stehender, öffentlicher Autorität und Sanktionsgewalt: es muß mit dem Gerichtsurteil die Möglichkeit seiner Durchsetzung verbunden sein. Andererseits geht der staatliche Eingriff im schwersten Fall noch am wenigsten weit: die Selbsthilfe wird bei Mord nur voribergehend aufgehalten (die eigentliche Hinrichtung (durch eine Behörde) gehört einer späteren Zeit an). Und nur die Blutsverwandten können Anklage erheben; noch im 4. Jahrhundert kam es vor, daß Mord nicht strafrechtlich verfolgt werden konnte, weil der Erschlagene keine Angehörigen hatte. Das noch deutlich erhaltene Vorstaatliche beim Blutrecht zeigt sich auch beim Recht auf Vergebung: Die Angehörigen konnten sich mit einem Sühnegeld begnügen, der Sterbende konnte dem Täter verzeihen und ihn damit vor Befleckung und daher Rache schützen (16).

Die noch nicht vollständig erreichte Verdrängung der ,Privatjustiz“ erklärt auch die sprichwörtliche ,drakonische Strenge' der ,mit Blut geschriebenen' Gesetze Drakons, (17) auch bei anderen Delikten, z. B. Diebstahl: sie war Voraussetzung für eine Ablösung der Selbsthilfe. Noch in ,historischer', d. h. schriftlich überlieferter Zeit kann in einigen Gebieten der nachts überraschte Dieb mißhandelt, verwundet oder getötet werden, ganz wie es dem Geschädigten zumute ist. Entkommt der Dieb, wird er mit Hilfe der Nachbarn verfolgt; Hausbewohner müssen die Hausdurchsuchung zulassen. Entsprechendes gilt für die Abwehr bei Mordversuch, Raub

16 Vgl. den folgenden Vorfall in Saudi-Arabien 1973: „Nach dem koranischen Scharia-Recht wird die Todesstrafe nicht vollstreckt, wenn die geschädigte Partei vergibt. Im November sollte in Dschidda ein junger Mann hingerichtet werden, der einen Gleichaltrigen im Streit getötet hatte. Der Henker hatte schon zum Schlag ausgeholt. Da stick dic Mutter des Toten unter ihrem Schleier hervor, daß nun kein Blut mehr fließen solle. Der Verurteilte war daraufhin frei. Eine Ambulanz brachte ihn mit heulender Sirene in eines der modernen Krankenhäuser zur Behandlung scines Schocks". (Der Spiegel, Nr. 53/1973, S. 58).

17 Diese sprichwörtlichen Ausdrücke stammen aus der Antike - auf entwickelterem Niveau wandte man sich schaudernd von der Grausamkejt der frühen Gesetzgeber ab. 
und auch für Enebruch, der als Eigentumsverletzung gilt. Gerade beim Ehebruch werden auch die ersten Versuche eines gesetzlichen Eingreifens gut sichtbar, das ja mit der Festlegung des Tatbestandes beginnen muß. Was wir mit verminderter $\mathrm{Zu}$ rechnungsfähigkeit bezeichnen würden, wird in einem Gesetz von Tenedos in der Weise ausgedrückt, daß der Ehemann zur Tötung die Axt benutzen müsse. Denn die Axt war das Werkzeug, das im Innern jedes Hauses sofort zur Hand war; andere Waffen mußten erst herbeigeholt werden, was den Vorsatz unterstellt. In die Zeit des Solon führt uns ein diesem zugeschriebenes Gesetz, wonach das Racherecht nur bei der Ertappung in flagranti eintrat. Die Bestimmung des Tatbestands ist hier schon fortgeschrittner; denn wenn bei dem Gesetz von Tenedos das Merkmal ganz äußerlich aus der Art der Rache gewonnen ist, tritt bei dem attischen Gesetz das Racherecht nur ein, wenn der Ehebrecher ,Glied im Glied haben" angetroffen wird (18).

Den Übergang von der gesetzlichen Einschränkung des Tatbestands zur Anerkennung der staatlichen Gerichtshoheit läßt noch deutlich das Apagogé-Verfahren des athenischen Rechts erkennen. Ein Solon zugeschriebenes, vermutlich älteres Gesetz bestimmte, daß der Dieb mit den gestohlenen Gut auf dem Rücken zur Richtstätte, den ständig anwesenden Archonten geschleppt wurde (apagogé = Wegführung); die Vertreter der Gemeinde übernehmen die Bestrafung. Hier wird die Selbsthilfe noch nicht einfach verboten, sondern auf einen Weg gelenkt, der bei der Anerkennung eines öffentlichen Strafrechts endet. Der Angeklagte hat die Möglichkeit, anders als bei der reinen Selbsthilfe, die Rechtsmäßigkeit seines Anspruchs zu vertreten; ein entscheidender Schritt auf die Rechtssicherheit hin. Aus dem Rächer ist schon der Kläger geworden. Auch bei der Entwicklung der Bußen ist diese Entwicklung erkennbar. Wenn der in seiner Ehre Geschädigte auf die Rache an der Person des Diebes, Ehebrechers usw. verzichtete, konnte dieser sich mit einer Bußeleistung sozusagen freikaufen (vgl. das germanische Wergeld und Entsprechendes im altrömischen Zwölftafelgesetz); mit dem Auftreten des Geldes konnte es in Drachmen festgesetzt und sehr differenziert werden. Diese Festsetzung durch ein Gesetz ist allein schon eine Einschränkung der Selbstherrlichkeit des Rächers. Deutlich wird der Schritt zu einer Strafe im eigentlichen Sinn, wo die Buße zu einem Teil oder ganz an die Gemeinde geht (wo solche Strafen regelmäßig gezahlt werden, dürften sie in aller Regel den Gebrauch von Münzgeld voraussetzen). So teilt das Solonische Gesetz über üble Nachrede die Buße zwischen Kläger und Staat; nicht so sicher datierbar ist der häufige Klagetyp, wegen Mißhandlung,, wo die Strafsumme restlos an den Staat geht (und Popularklage herrscht, vgl. unten.) Daß die Verletzung der körperlichen Unversehrtheit in Athen klar zum Bereich des öffentlichen Strafrechts gehört, verdient besondere Hervorhebung. Zugleich ist hier allerdings ein Hinweis auf die Beschränktheit der öffentlichen Strafgewalt notwendig, um vor modernisierender Überschätzung zu bewahren: es stehen nur recht grobe Instrumente zur Verfügung, also vor allem die Buße (zu Solons Zeit sicher noch 
weit überwiegend nicht in Geld, sondern in Naturalien), die Ehr- und Friedlosigkeit bzw. die Verbannung und die Todesstrafe, gewöhnlich verbunden mit Gütereinzug. Es fehlt also so gut wie völlig die Gefängnisstrafe, außer als Untersuchungshaft. Die geringe Differenzierung der Strafen wurde noch dadurch gesteigert, daß die Definition der Tatbestände nie die uns selbstverständliche Präzision erreichte und daß die Bestimmung des Strafmaßes weitgehend dem Ermessen der Richter überlassen blieb (vgl. den Prozeß gegen Sokrates wegen, Gottlosigkeit') (19).

Eine weitere, deutlich auf das Gemeinwesen bezogene Strafe schreibt Aristoteles (20) dem Solon zu: wer bei bewaffneten Klassenauseinandersetzungen in der Polis weder auf die eine noch auf die andere Seite sich schlage, der solle mit ,Ehrlosigkeit ${ }^{6}$ bestraft werden und seine Rechte als (politischer) Bürger verlieren, also vor allem das Recht zur Teilnahme an der Volksversammlung. Andere Vergehen, die auf diese Weise geahndet wurden: Nichtzurückzahlung von Staatsschulden, Ungehorsam gegen die Gesetze und Bestechung bei Beamten - also alles Vergehen gegen die Gemeinde. Außerdem werden Vergehen gegen die guten Sitten bestraft (z. B. Mißhandlung der Eltern).

Eine entscheidende Ausdehung der persönlichen Freiheit und damit der Voraussetzung einer Freiheit des Willens (denn Sklaven unterstanden prinzipiell der unmittelbaren Gewalt ihres Herrn) bedeutet die berühmte und bereits erwähnte ,Lastenabschürtlung durch Solon im Jahr 594/93. Indem er die versklavten und verkauften Bauern befreite und die Personalexekution fiur die Zukunft ausschloß (21), erhöhte sich die Zahl der dem Gesetz und der Gerichtsbarkeit unterworfenen Vollbürger erheblich (vermutlich auf mehr als die Hälfte der männlichen Bevölkerung Attikas). Solon selbst berichtet:

Dem Edlen und Gemeinen schreib ich gleich Satzung, gerechter Spruch gilt nun für jeden Streit (22).

Für die wachsende Anerkennung der Autonomie der Person sprechen vor allem zwei

19 Vgl besonders E. Ruschenbusch, DIKASTERION PANTON KYRION. In: Historia, Bd. 6 (1957), S. 257-74.

20 Aristoteles, Staat der Athencr, VIII, 5.

21 Daß Solon die Personalexekution überhaupt und für dic Zukunft abgeschafft habe, wird von verschiedenen Autoren bezweifelt; vgl. dazu Cataudella, Atene fra il VII e il VI secolo, $\mathrm{a}_{0} \mathrm{a}_{8} \mathrm{O}$.

22 Fragment 24, 18 Diehl, nach der Übersetzung von Latte, Der Rechtsgedanke ... a.a.O. S. 245. Latte bemerkt dazu: „Die Einführung geschriebener Gesetze bedeutet zunächst Gleichheit aller Vollbürger vor dem Gesetz. ... Isonomie, Gleichheit der Rechte, heißt das Schlagwort dieser Jahrhunderte". (Ebd.) Vgl. auch die Verse des Euripides: „Feindselger ist dem Staate nichts denn der Tyrann;/Zuerst: Dort sind Gesetze nicht gemeinsam Gut,/Gewalt hat einer, der besitzet das Gesetz/Allein für sich - und dies ist nimmermehr gerecht" (wörtlich: gleich)./,Jedoch, wenn aufgezeichnet die Gesetze sind,/ Dann hat der Schwache und der Reiche gleich das Recht,/Berufen mögen sich die Schwächeren darauf/Gen einen Mächtgen, wenn er einen hat gekränkt./Und es obsiegt des Großen der Geringre, hat er Recht“. (Euripides, Die Flehenden, Verse 429 ff. Nach der Übersetzung von $F$. Stoessl, Bd.2, Zürich und Stuttgart, 1968) 
Bereiche aus der solonischen Gesetzgebung: Aus dem ,bürgerlichen Recht' (23) das Testamentsgesetz, sodann das Institut der Popularklage. Die Popularklage, auch später charakteristisch für das attische Recht, gestattet jedem (Voll-)Bürger eine strafrechtliche (ebenso wie eine privatrechtliche) Klage einzuleiten (eine öffentliche Anklagebehörde hat es in Athen nicht gegeben). Während bei dem erratischen Block des Blutrechts das Klagerecht bei der Gruppe der Blutverwandten blieb, wurde also in allen übrigen Fällen von der Voraussetzung der Verwand tschaft abgesehen. Jeder einzelne Bürger sollte aus den alten Gruppenbeziehungen befreit und für das Recht verantwortlich sein; die Stoßrichtung der Maßnahmen ist klar: „Indem Solon ein Recht, das bisher in jedem Fall nur einer bestimmten Gruppe zustand, allen Bürgern einräumte, zerschnitt er ein Band, das dieše Verbände innerhalb des Staates zusammengehalten und abgesondert hatte: Es war ein Versuch, die Solidarität der Genossenschaften durch ein Gemeingefühl aller Bürger zu ersetzen“ (24).

Historisch ist offensichtlich - das ließe sich auch an der fruihbürgerlichen Geschichte des modernen Europas zeigen - die Emanzipation des bürgerlichen Individuums gebunden an die Entstehung einer sanktionsmächtigen öffentlichen Instanz, einer selbst nicht mehr unmittelbar von den Handlungszwängen des Warenverkehrs abhängigen zentralen Gewalt, die nicht ohne weiteres allerdings ein politi-

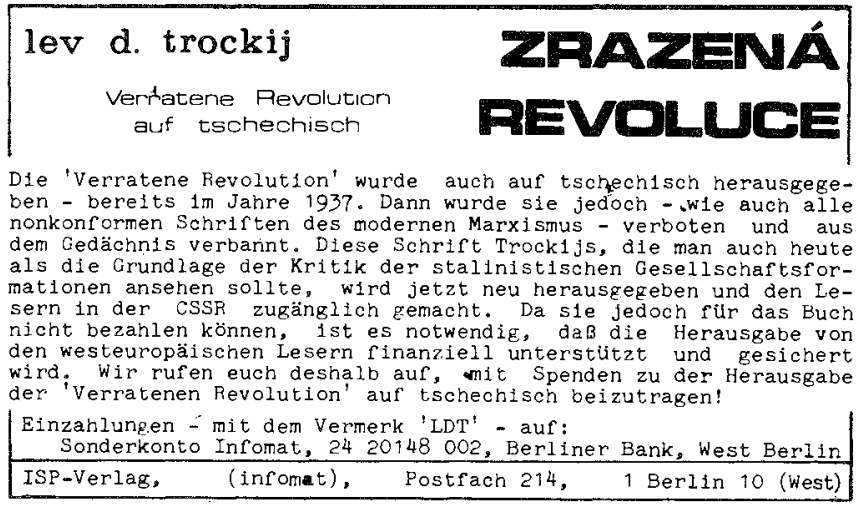

23 Der Begriff ist nur mit Vorbehalt anzuwenden, vgl. die Ausführungen weiter unten. Zum bürgerlichen Recht sind bei Solon zu rechnen: die familienrechtlichen Bestimmungen, die Regelung der Grunddienstbarkeiten, der Bebauung und der Bepflanzung von Grundstücksgrenzen, das Gesetz ïber Vereinsautonomie. (Nach E. Ruschenbusch, PHONOS. Zum Recht Drakons und seiner Bedeutung für das Werden des athenischen Staates. In: Historia Bd. 9 (1960) S. 129-154, hier S. 148; vgl. SOLONOS NOMOI. Die Fragmente des Solonischen Gesetzeswerkes mit einer Text- und Überlieferungsgeschichte. Hrsg. E. Ruschenbusch. Wiesbaden 1966, S. 25 f.

24 Latte, Beiträge zum griechischen Strafrecht, a.a.O. S. 264 f. Lat te weist darauf hin, daß dies auch die Absicht der Reformen des Kleisthenes gewesen ist, auf die in unserem Zusammenhang nicht näher eingegangen werden kann. (Kleisthenes machte das Territorialprinzip anstelle der alten gentilizischen Einteilung zur Grundlage des Bürgerrechts und zerstörte so die Bindungen an die herkömmlichen, vielfach klassenmäßigen Gruppen). 
scher Apparat in dem uns meist allzu selbverständlichen Sinn sein muß (25). Diese Aufgabe zumindest muß jedoch geleistet werden, und sei es auch durch einen absoluten Fürsten, ,Tyrannen', oder durch eine Körperschaft etwa nach Art einer Kaufmannsgilde oder selbst eine Stammesreligion (die für jüdische Kaufleute viel von dem verpflichtenden, ja zwingenden Charakter jener Instanz übernehmen konnte). Dabei ist in keiner Weise an ein einseitiges Abhängigkeitsverhältnis zu denken, vielmehr an einen umfassenden Prozeß, in dem nur zeitweise einzelne Momente führend sein mögen. In der athenischen Entwicklung ist übrigens schon früh die Unterscheidung von Rechtsetzung und Rechtdurchsetzung erkennbar, wenngleich nicht in Gestalt deutlich unterschiedener, ja gegeneinander verselbständigter staatlicher Gewalten. Im übrigen ist mit diesen Feststellungen noch keineswegs gesagt, daß der ,Staat der Athener ${ }^{6}$ wesentlich durch diese ,rechtstaatlichen ${ }^{6}$ Aufgaben bestimmt war; darauf ist unten noch näher einzugehen.

Die Emanzipation des Individuums aus der traditionellen ,Sippenhaftung und seine Anerkennung als Privateigentümer wird als Perspektive noch deutlicher erkennbar im Testamentsgesetz Solons (26). Für den Fall des Fehlens männlicher Nachkommen wird dem Erblasser hier Testierfreiheit zuerkannt, d. h. das Eigentum wird ein wenig aus seiner bedingungslosen Unterwerfung unter den ökonomisch-religiös-blutsmäßigen Zusammenhang der Großfamilie befreit. Besonders bemerkenswert ist hier, daß das Testament nach dem solonischen Gesetz bei Willensmängeln angefochten werden kann, z. B. bei Schwachsinn und bei Gewalteinwirkung. Damit sind schon zwei bis heute wesentliche Voraussetzungen für die Willensfreiheit der Person festgestellt (freilich charakteristisch unbestimmt, denn es werden keine Kriterien genannt, was zu endlosen Anfechtungsklagen geführt hat; überhaupt hat es im griechischen Recht nie eine gesetzliche Theorie der Willensmängel gegeben).

25 Vgl. zu dieser historischen Feststellung die (begriffliche) ,Ableitung“ der „Funktion Zwang sgewalt" aus der Warenform bei Blanke/Kastendiek/Jürgens (Zur neueren marxistischen Diskussion ..., a.a.O. S. $69 \mathrm{ff}$, , bes. $71 \mathrm{f}$.). (Die Argumentation hätte hier die Notwendigkeit dieser Zwangsgewalt schärfer herausarbeiten konnen: 1. Ist den lauschsubjekten von vornherein auch der Widerspruch zu der von ihnen als Charaktermasken vollzogenen Austauschbeziehung immanent? Nämlich auf der Stufe der Entwicklung, wo das Geld in seinen ersten beiden Formbestimmungen entwickelt ist? Oder kurz: sind die Warenaustauscher als solche bereits egoistische Individuen? (Das wäre der strikte Sinn einer Ableitung der Funktion Zwangsgewalt aus der Warenform, Blanke/Kastendiek/Jürgens S. 72). 2. Wird dieser Widerspruch vielleicht erst mit dem Übergang 7um Geld in seiner dritten Bestimmung, als Interesse an der Ubervorteilung zwecks Geldakkumulation, entwickelt? Ist die Rede von der Rechtsperson, die ihre besonderen Bediurfnisse und Interessen domestiziert, indem sie sich auf cin Allgemeines bezicht, überhaupt erst sinnvoll bei Entwicklung aller Bestimmungen der einfachen Zirkulation? Ist nicht diese Domestizierung der Besonderheit durch das Allgemeine, der Staat' in jeder einzelnen Person, noch bevor er als gesonderte Funktion hervortritt? 3. Unterstellt diese Entwicklung aller Bestimmungen der einfachen Zirkulation nicht den Übergang zum Kapital als Produktionsverhältnis? Muß nicht erst das „Wertgesetz" bzw, das entwickelte Kapitalverhältnis eingeführt sein, um die "Durchsetzung des Rechtsgesetzes" zu begründen? (Zitate: Blanke/Kastendick/Jürgens, S. 72).

26 Solon, Fragment 49,50, nach der Ausgabe von Ruschenbusch, a.a.O. 
Von verschiedenen Autoren werden weitere Zugnisse für die, ,grundsätzliche Anerkennung des Privateigentums" (daneben auch von Leben, Freiheit, Ehre usw.) angeführt (27), z. B. die Unantastbarkeit des Hauses oder der seit dem frühen 7. Jahrhundert übliche Eid der Jahresbeamten, in dem die Anerkennung aller bestehenden Eigentumsverhältnisse proklamiert wird. Die verschiedenen Zweige des athenischen Rechts sind dabei nach den Kriterien des entwickelten römischen Rechts untersucht worden, ein leicht zu Fehleinschätzungen verführendes Verfahren; es seien einige charakteristische Titel genannt: Weiss, Griechisches Privatrecht auf rechtsvergleichender Grundlage, Ruschenbusch, Untersuchungen zur Geschichte des athenischen Strafrechts, Kahrstedt, Studien zum öffentlichen Recht Athens (28). In verschiedenen neueren Untersuchungen sind durch eine eindringendere, z. T. durch die Ethnologie und die vergleichende Rechtsgeschichte angeregte Interpretation allerdings mehr die Schranken der Entwicklung des griechischen und auch des attischen Rechts herausgearbeitet worden (29). Gerade weil sich diese Arbeiten hauptsächlich auf die Rechtentwicklung der klassischen und hellenistischen Zeit beziehen, sind sie interessant für die Schranken selbst der späteren Entwicklung des griechischen Rechts, die den Begriff des Privatrechts selbst fragwürdig werden lassen (und daher auch den Begriff des Staatsrechts, ja überhaupt des Staates, der Souveränität, des Rechts, worauf abschließend einzugehen sein wird). Es soll dies im folgenden exemplarisch an der beschränkten Entwicklung der Begriffe des Privateigentums und des Vertrags gezeigt werden; die volle Emanzipation von gebundenen Formen des Eigentums zum Privateigentum ist ja die Voraussetzung für die Konstitution einer bürgerlichen Gesellschaft im engeren, im modernen Sinn des Wortes.

Zunächst fällt bei genauerer Betrachtung auf, daß es gar keinen Begriff für Privateigentum gibt (und daher auch keine Unterscheidung zwischen Eigentum und Besitz), durchaus im Unterschied vom entwickelten römischen Recht (dominium, dominium ex jure Quiritium). Das Wort usia meint sowohl, Vermögen, Habe, Eigen-

27 U. Kahrstedt, Studien zum öffentlichen Recht Athens. Teil I: Staatsgebiet und Staatsangehörige in Athen. Stuttgart 1934 (= Aalen 1969), S. 129 ff., hier S. 138.

28 E. Weiß, Griechisches Privatrecht auf rechtsvergleichender Grundlage. 1. (einziger) Band: Allgemeine Lehren. Leipzig 1923 (= Aalen 1965); U. Kahrstedt, Studien zum öffentlichen Recht Athens. Teil I, a.a.O.; Teil II: Untersuchungen zur Magistratur in Athen. Stuttgart 1936 (= Aalen 1969); E. Ruschenbusch, Untersuchungen zur Geschichte des athenischen Strafrechts, Köln, Graz 1968.

29 Vgl. zum folgenden insbes.: F. Pringsheim, The Greek Law of Sale, Weimar 1950; H. J. Wolff, Die Grundlagen des griechischen Vertragsrechts. In: Zeitschrift der SavignyStiftung für Rechtsgeschichte, Rom. Abt., Bd. 74 (1957), S. 26-72; Gernet, Sur la notion du jugement en droit grec, a.a.O.; Jones, The Law and Legal Theory of the Greeks, a.a.O., Kapitel XI. 
tum ${ }^{6}$ wie ,Persönlichkeit, Wesen'. Ausdrücke, die ,jemand gehören ${ }^{6}$ bezeichnen (30), beziehen sich wesentlich auf die tatsächliche physische Kontrolle und auf einen gewissermaßen auch psychischen Anspruch auf eine Sache. Am nächsten im Deutschen kommt noch das Wort ,Haben ${ }^{6}$ oder das schwäbische ,mei eigen ${ }^{6}$, ,mei Sach'. $\mathrm{Zu}$ erinnern ist übrigens auch daran, daß die erlaubte Selbsthilfe sich auch für uns auf das eigene Selbst als körperliche Person wie auf körperlich vorhandenen Besitz bezieht (31). Auch etwa das Wort chrémata, oft übersetzt als ,Geldmittel', ist vieldeutig; sein Stamm verweist auf den Nutzen für den Gebrauch, auf das Bedürfnis; es kann dann die Masse nützlicher Gegenstände sein, das Vermögen, der Besitz, die Mittel; in bestimmtem Sinn dann auch die Geldmittel, das Geld, die Geldsumme, ja die Schulden oder die Waren (32).

Wie wenig der Begriff des Privateigentums im Griechischen entwickelt ist, zeigt sich auch deutlich an den Rechtsmitteln zur Wiedererlangung beeinträchtigten oder verlorenen Eigentums. Immer ist es der Besitzer, der gezwungen ist, seine Ansprüche zu rechtfertigen; durch Klage konnte nur das relativ bessere Recht, nicht aber ein absolutes und ausschließliches Eigentumsrecht festgestellt werden (so war immer möglich, daß ein Dritter mit noch besserem Recht auftrat). Nur in dieser Form wird in Urteil zum Eigentumsrecht Stellung genommen, also keine Anerkennung und Bestätigung eines subjektiven Rechts ausgesprochen; das Urteil gilt vielmehr noch als Abschluß eines Streits. Und die Wiederherstellung des verlorenen ,Vermögens $s^{6}$ war eine Wiederaneignung im wörtlichen Sinne: es gab keine direkte staatliche Hilfe bei der Vollstreckung, sondern der Obsiegende erhielt durch das Urteil nur ein Zugriffsrecht, er mußte sein Recht selbst herstellen, z. B. durch persönliche und gewaltsame Wegnahme vom Vorbesitzer oder durch Zugriff auf den Schuldner. Erst wenn dieser das seinerseits mit Gewalt verhinderte, wurde ein besonderer Klagetyp möglich (der eine Buße in Höhe des Streitwerts an den Staat vorsah); darauf konnte erneut zur Selbsthilfe geschritten werden. Diese ,Eigentumsklage" war wesentlich, ,a form of execution, of enforcing rather than establishing rights, a means of realizing the power of self-help which early law regarded as bound up with that sphere of power which was involved in its concept of proper-

30 Ta idia einai emou, emautou einai, ta emou, hyparchei moi.-

Eine ähnliche Unterentwicklung grundlegender juristischer Kategorien ließe sich auch am altrömischen Recht zeigen, während das entwickelte römische Recht, wie es uns in der Kodifikation durch den spätrömischen Kaiser Justinian (6. Jahrhundert) vorliegt, das hellenistische Recht in wichtigen Punkten durchaus hinter sich gelassen hat.

31 VgL BGB $\S \S 227,859 ;$ StGB $\S 53$.

32 Vgl H. G. Liddell/R. Scott/H. S. Jones, A Greek-English Lexicon, Oxford 1940, unter chrona. - Diesen Doppelcharakter hat auch unsere Sprache vielfach noeh bewahrt, womit gewissermaßen die Schwierigkeit angedeutet ist, alles rücksichtslos vom Standpunkt des Werts aus zu betrachten. So etwa, wenn heute angesichts massenhafter Vernichtung von Äpfeln oder Tomaten gesagt wird: ein Jammer, daß solche Werte verniehtet werden - hier sind dann die nützlichen, genieß̧baren, unmittelbar insere Beciürfnisse ansprechenden Gebrauchswerte gemeint, nicht die Kapitalwerte, das nicht verwertbare Warenkapital des Tomatenkapitalisten. Ähnlich bei der Feststellung: jemand ist mir viel wert. 
ty ${ }^{66}(33)$. Es kommt in diesem Verfahren sehr deutlich die konkret-individuelle Beziehung zum Ausdruck, die der Eigentümer zu seiner ,Sache' hat (34). Diese Sache galt als Teil seiner Persönlichkeit (35), genauer: als Teil seiner gesellschaftlichen Existenz in der bestimmten Funktion der Lebenserhaltung im Gemeinwesen der Polis. Sein ,Vermögen' ist ein Teil seines persönlichen Herrschaftsbereichs innerhalb dieser spezifischen Gesellschaftsform der Polis, nämlich in dem besonderen Sinn, den dieser Bereich für den freien Athener hat: als Herr eines Oikos, einer Hauswirtschaft mit Grund und Boden, mit Haus und den notwendigen Werkzeugen und Gebrauchsdingen, mit ihm untertanen Menschen und Tieren (darunter Sklaven, in eingeschränkter Weise auch Frauen und Kinder) (36).

Diese konkrete Beziehung zum Eigentum, die noch weit entfernt ist vom ius

33 Jones, The Law and Legal Theory of the Greeks, a.a.O. S. 204.

34 Am deutschen Wort ,Sache" läßt sich noch die Entwicklung von der konkreten zur abstrakten Beziehung illustrieren. Sache (lateinisch res) ist der juristische Terminus für Ware bzw. Privateigentum. Zu ihr hat man als Person, d.h. als Privateigentümer cin ssachliches" Verhältnis, kann sie ohne Schmerz verkaufen. Im schwäbischen mei Sach hingegen steckt noch deutlich die konkrete Beziehung: gemeint wird damit etwa ,meine Angelegenheiten, Aufgaben', ,die nützlichen Dinge für eine bestimmte Tätigkeit', überhaupt, was mir zugehört'. Man ist dabci immer auf einc konkrete Aktion bezogen, z. B.: ,i han mei Sach zamma' sagt eine Frau, wenn sie vor dem Baden Handtücher, Seife usw. zusammengelegt hat. Das hoehsprachliche Wort, sachlich' wird im Schwäbischen nicht gebraucht. Solche Beobachtungen lassen sich an viclen Dialektausdrücken machen. Dialekte ragen gewissermaßen aus der vorkapitalistischen Vorstufe in unsere Gcsellschaft hinein. Ihre vorbürgerlichen, häufig bäuerlichen Sprachformen drücken viel stärker die direkten, ,emotionalen' (wie der distanzgewohnte Bürger sagt) Beziehungen zu Menschen und übriger Umwelt aus. Hochsprachen dagegen sind nicht nur Mittel bürgerlich-nationaler Vereinheitlichung, sondern Sozialisationsmittel für kühl-distanziertes Verhalten, Abstraktion und Rücksichtslosigkeit gegenüber eigenen und fremden ,Gefühlen" (die Einübung in die klassische lateinische Hochsprache hat jahrhundertclang diese Aurgabe erfullt; heute sind die Hochsprachen entsprechend, logisch" geprägt; nicht zufällig haben die absolutistischen Fürsten Lateinschulen errichtet, um die juristische Schulung der Diener des Allgemeinen vorzubereiten). In der Entwicklung solcher, sachlichen' Beziehungen steckt ein durchaus progressives Moment, nicht zuletzt die Voraussetzung von Wissenschaft überhaupt. Ein Fortschritt, der freilich dort an schmerzhafte Schranken stößt, wo die distanziert veräußerte Sache unablösbarer Teil der cigenen Existenz, z. B. das eigene Arbeitsvermögen ist.

35 Im vorrcvolutionären China hatte der Verkäufer zeitlebens das Recht, zu bestimmten Festen seiner verkauften Sache ,Scufzerbilletts' anzuheften und damit seinen Schmerz über die Veräußerung auszudrïcken, die ,Veräußcrung' also eines Teils seines Selbst.

36 Übrigens ist noch bei dem frühbürgerlichen englischen Philosopen John Locke der Begriff Property ähnlich schillernd, er meint sowohl Herrschaft/Eigentum über den eigenen Körper wie über die Gebrauchsdinge der Umwelt, dic durch eigene Arbcit der natürlichen Umwelt abgewonnen sind. Locke läßt freilich den Begriff sich entwickeln, sodaß einerseits die Macht über den eigenen Körper als Eigentum an dessen Arbeitsvermögen erscheint, andererseits fleißig-rationale Menschen durch Aufhäufung erarbeiteter Gebrauchsdinge sich dic zeitweise Verfügung über die Arbeitskraft anderer eintauschen können, und daher Akkumulation möglich wird. Er ist daher schon deutlich ein Vertreter der modernen bürgerlichen Gesellschaft. Vgl. Locke, Two Treatises of Government, 
utendi et abutendi des entwickelten römischen Rechts (37) und die prinzipiell auf die Aufgaben als Athener, als Polities, Vollbürger der Polis Athen bezogen bleibt, drückt sich auch darin aus, daß der für das römische Recht zentrale Begriff der obligatio, (Schuldverhältnis, Verpflichtung), der Voraussetzung des Schuldrechts, im griechischen Recht nicht ausgebildet worden ist, daß die Kategorie des Vertrags vergleichsweise unentwickelt geblieben ist. Zwar war der Vertrag, der im allgemeinen mündlich vor Zeugen geschlossen wurde, durchaus bekannt, sowohl im alltäglichen Kredit- und Darlehensverkehr wie in den auswärtigen Beziehungen; auch wurde die Notwendigkeit einer öffentlichen Sanktion klar gesehen (38). Jedoch bedurfte er grundsätzlich einer, realen' Basis, d.h. er wurde zu einem bestimmten Zweck abgeschlossen, dessen Nichterfuillung die Haftung des Schuldners begründete. Nur diese ,Schädigung ${ }^{6}$ konnte eine Klage begründen, die einen vergeltenden Zugriff ermöglichen sollte. Die bindende Wirkung konnte also nicht direkt aus dem Konsens, dem in Vertragsschluß bekundeten Zusammenhang mehrerer Willenserklärungen abgeleitet werden, wie es der Konsensualvertrag des entwickelten römischen Rechts vorsieht. Die Entstehung der Verpflichtung gilt als Wirkung der Überlassung des konkreten Gutes, z. B. eines Grundstücks, bzw. als Wirkung der Schädigung durch Nichtherausgabe usw.

Die Dinge treten sozusagen noch ganz überwiegend in ihrer Gebrauchsqualität in Erscheinung, weil sie als Waren noch nicht voll entwickelt sind; deshalb sind ihre Besitzer auch noch kaum in der Lage, sie losgelöst von ihren konkreten Interessen und Bedürfnissen bloß als Träger von Wert, als Waren bzw. als Kapital zu betrachten. Die ,Herren' dieser Dinge betrachten daher einander noch nicht als bloße Repräsentanten von Waren und Geld, als autonome Privateigentümer, deren Willen nur Ausdruck der Waren und ihrer bereits mehr oder weniger verselbständigten Bewegung sind. Wo dies aber doch schon geschieht, wird es abgewehrt und abgelehnt - die Heftigkeit der Ablehnung mag immerhin bezeugen, wie sehr sich die Autonomie der Wertbewegung bereits bemerkbar machte (39). Hier ist allerdings die Frage anzufügen, ob sich die Mitglieder selbst einer entwickelten kapitalistischen Gesellschaft rein als autonome Privateigentümer, als bloße Repräsentanten von Waren und Geld, bzw. der in diesen Formen sich äußernden Bewegung des Werts betrachten und behandeln können. Sie sind diese Rechtspersonen bzw. Charakter-

Second Treatise. Hrsg $P$. Laslett, Cambridge $1970^{2}$.

37 Vgl. die Formulicrung der Eigentumsfreiheit im BGB (\$903): ,, Der Eigentümer einer Sache kann, soweit nicht das Gesetz oder Rechte Dritter entgegenstehen, mit der Sache nach Belieben verfahren und andere von jeder Einwirkung ausschließen". (Keine Hervorhebung im Original).

38 Schon Herodot (Mitte des 5. Jahrhunderts) bemerkt: ,Ohne zwingende Sicherung werden Verträge nicht sicher bleiben", bezogen freilich auf Verträge zwischen Fürsten bzw. Staaten (Herodot, Historiae, I, 74). In den überlieferten Gerichtsreden (vor allem 4. Jahrhundert) ist es eine stehende Redewendung, daß Vertragsparteien sich an ihre Versprechen zu halten haben, und Aristoteles hält gesellschaftlichen Verkehr ohne Gerichte für ausgeschlossen; vgl. Jones, The Law and Legal Theory of the Greeks, a.a.O. S. 216.

$\mathrm{Vgl}$ die eingangs zitierten Äufserungen von Platon und Sophokles. 
masken doch immer nur soweit sie ihre unmittelbaren Bedürfnisse - wie immer gesellschaftliche vermittelt diese sind - zuriickdrängen, sich moralisch domestizieren auf jenes Allgemeine hin, das ihre Gesellschaftlichkeit ist (und das ihnen äußerlich als Staat gegenübertritt, ob nun durch ihre freiwillige Übereinkunft begründet oder als unvermeidlicher Not- und Verstandesstaat, ja Leviathan).

Wie sehr etwa der Gläubiger am attischen Recht noch eine ganz konkrete Beziehung zu seiner Sache hat, zeigt sich an der Vorstellung, daß das Darlehen nicht in das Eigentum des Schuldners übergeht, diesem zur freien Verfügung (und das heißt zur Vermehrung mit beliebigen Mitteln) übereignet ist, sondern Eigentum des Gläubigers bleibt (unjuristisch auch noch bei uns, wenn jemand, sein Geld ${ }^{6}$ zurïckfordert, das er jemand geliehen hat)., Wo immer in den attischen Reden von Darlehen gesprochen wird, da hören wir den Darlehensgeber sagen, daß der Entleiher sein Geld habe und ihn dadurch, daß er nicht zahle, um sein Geld beraube (aposterein). Von der scharfen Abgrenzung des entwickelten römischen Rechts, bei welcher das als mutuum oder depositum irregulare kreditierte Geld ins Eigentum des Schuldners übergeht, der dann aufgrund der angeknüpften Schuldbeziehung auf Rückgabe haftet, ist nichts zu bemerken ${ }^{6}(40)$. Vielmehr gibt der Gläubiger das Darlehen, auch wenn es Geldform hat, zu einem bestimmten Zweck, nicht zur beliebigen, allerdings zinstragenden Verwendung; die Verletzung dieses Zwecks, die Schädigung durch Nichtausführung der verfügten und vom Verfügungsgegner angenommenen Bedingungen, nicht der einfache Bruch des gegebenen Versprechens, begründet das Recht zum gerichtlichen Vorgehen. In den Gerichtsreden hebt Demosthenes selbst im Falle des Seedarlehens die reale Natur des vom Beklagten "freiwillig in Empfang genommen und dann weggenommenen Talents" hervor. Beruhte die Beziehung nur auf, Glauben", wäre weder Pfand- noch Bürgschaft geleistet, so wäre eine Klage strenggenommen nicht möglich (41).

Der griechische Vertrag kennt also noch nicht die volle Anerkennung des freien Willens der Vertragschließenden, der abstrakten Rechtspersonen, im Sinne

Wolff die Grundlagen des griechischen Vertragsrechts, a.a.0. S. $508 \mathrm{f}$.

Tatsächlich gibt es nach Aristoteles (Nikomachische Ethik, IX, 1, S. 1164 b 13 f.) in einigen Poleis keine Möglichkeit der Klage für den Gläubiger von Gelddarlehen; entsprechend wollte Platon, dafs im idealen Stat die meisten, freiwiligen Rechtsgeschafte " auf Gefahr des Gläubigers erfolgen sollten, Normalfall sollte das Bargeschäft scin (Platon, Staat, Buch VIII, S. 556 a, b; Die Vertragsvorstellung blieb im griechischen Recht immer im Umkreis des Barkaufs stehen; obwohl Kreditkauf und Anzahlungskauf spärestens seit der klassischen Zeit eine selir wichtige Rolle gespielt haben, sind sie nicht in der Form des Vertrags ausgedrückt worden. Vgl, zusammenfassend Jones, The Law and Legal Theory of the Greeks, a. a. O. S. 228:,... there is good ground for supposing that Greck law, like early Roman and English law, considered sale as essentially an exchange of land or goods for money, a cash transaction giving no right to enforce payment on the one side or delivery on the other. It was a two-sided affair; but there could be no question of any outstanding obligations arising from the simple fact of agrcement. In law the sale was complete or it was nothing and it was not complete until the price hat been paid...". Die wichtigste Untersuchung zur Frage des Barkaufs und seiner rechtlichen Ausdrucksform: Pringsheim, The Greek Law of Sale, a. a. O. 
des römischen Rechts; er ist nicht wirklich gegenseitig, sondern trägt noch deutliche Spuren der Ungleichheit der Beteiligten. Wenn also der Vertrag wesentlich ,ZZweckverfügung" (Wolff) blieb, so gilt das entsprechende für die Kategorie des Urteils und des Privateigentums: Das Eigentum, das als ein subjektives Recht um seiner selbst willen öffentlichen Schutz genießt und das im Urteil explizit bestätigt wird, ist dem griechischen Recht fremd geblieben. In diesem Sinn gibt es daher kein Privatrecht in der antiken griechischen Polis.

Diese Feststellung bezieht sich im übrigen ohnehin nur auf die männlichen Vollbürger; daß deren Frauen und Kinder und vor allem deren Sklaven nicht oder nur sehr beschränkt rechtsfähig waren, ist bekannt. Allerdings ist die Vorstellung völliger Rechtslosigkeit der Sklaven nicht richtig, besonders wenn uiber den Bereich des Privatrechts hinausgegangen und das (offentliche) Strafrecht und das Sakralrecht sowie das Handelsrecht berücksichtigt wird. Ủber die geminderte Rechtstellung der ansässigen und anerkannten Ausländer (Metöken) und der vorübergehend anwesenden Ausländer (Xenoi) kann Genaueres nur gesagt werden, wenn das Handelsrecht im engeren Sinn und der durch Verträge mit anderen Stadtstaaten bewirkte Rechtsschutz berücksichtigt wird; hier ist eine allmähliche Annäherung an den Status des Vollbürgers festzustellen, allerdings nicht hinsichtlich der politischen Rechte. Vielleicht sollte man aber die Konstatierung der beschränkten Entwicklung des griechischen Privatrechts und die Feststellung von der grundsätzlichen Rechtlosigkeit der Sklaven nicht einfach nebeneinander stehen lassen. Nur als These sei hier formuliert: die beschränkte Entwicklung des griechischen Rechts, die beschränkte und abgestufte Verleihung der bürgerlichen Rechte ist nur ein Ausdruck der Tatsache, daß die Masse der unmittelbaren Produzenten Sklaven und nicht freie Lohnarbeiter waren, daß die innere Struktur der Produktion vom Kapital noch fast gar nicht angestastet war. Das wirft allerdings die Frage nach der Basis für die höhere Entwicklung des römischen Rechts auf, das doch auch in einer Gesellschaft von Sklavenhaltern ausgearbeitet worden ist. Dem kann hier nicht im einzelnen nachgegangen werden. Immerhin seien einige Vermutungen geäußert: das römische Recht war schließlich Recht des römischen Weltreichs, das in seiner Blütezeit ein mittelmeerisches Welthandelsreich mit weiträumiger Arbeitsteilung, manufakturähnlicher Massenproduktion usw. war, die immerhin einen beachtlichen Teil des gesellschaftlichen Gesamtprodukts betrafen. In den langen Kriegen, die zur Errichtung einer kaiserlichen Herrschaft führten, wurde eine Form zentralisierter und kontinuierlicher staatlicher Souveränität herausgebildet, die der Republik und erst recht der tendenziell demokratischen Verfassung etwa der Polis Athen fremd war (zwei bekannte Indizien: Ersetzung der Volksarmee durch ein Berufsheer; Ersetzung der ungeregelten Privatplündenung eroberter Gebiete durch eine bïrokratische Reichsverwaltung). Diese absolute, in der Person des Imperator lokalisierte Souveränität (,Princeps legibus solutus') konstituierte zugleich eine allgemeine Unterworfenheit der römischen Büirger, vor der die internen Differenzierungen des Bürgerrechts und vor allem seine Abgeschlossenheit gegenüber der zunächst nichtbürgerlichen Reichsbevölkerung immer mehr zurücktrat (immer weitergehende Verleihung des Bürgerrechts, und damit die ,Weltgeltung ${ }^{6}$ des römischen bürgerlichen Rechts). Und auch 
der Unterschied zwischen Freien und Sklaven begann sich immer stärker zu verwischen, jedenfalls an den Grenzzonen (eine Entwicklung, die bereits in Athen und in der römischen Republik einsetzt). Einzelne hochqualifizierte Sklaven, ob freigelassen oder nicht, übten bedeutende Funktionen als, Graue Eminenzen ${ }^{6}$ aus, z. B. in der privaten Güterverwaltung und in der kaiserlichen Bürokratie; verbreiteter waren Freigelassene in ,bürge rlichen Berufen' (Lehrer, Sekretäre, Schreiber; weiter Handwerker und Händler). Alle blieben an ihre Herren in starker Loyalität gebunden, zumindest in erster Generation quasi hörig. Die Aufstiegsmöglichkeit, als Perspektive für viele Sklaven auch durch die Möglichkeit zur Vermögensbildung und damit vielleicht zum Selbstfreikauf eröffnet, darf natürlich nicht darüber hinwegtäuschen, daß die große Mehrheit der Sklaven, unten' blieb - wo sich freilich auch zunehmend viele Freie befanden. In der Spätantike wurde die (intern immer stark differenzierte Scheidung von Freien und Sklaven immer deutlicher zu einer ständischen Gliederung, welche sich im Recht als Unterscheidung zwischen, einfachen ${ }^{6}$ und ,besseren "Menschen niederschlug. Jedenfalls ist der zentralisierte ,Staatsapparat" des römischen Reichs gegenüber der Masse der Bevölkerung viel mehr verselbständigt, ,absolut', als der ,Staat der Athener'.

Damit sind wir bei der abschließend anzusprechenden Frage, ob dem athenischem Staat überhaupt der Begriff Staat angemessen ist, da ja offenbar die Kategorien der Person, des Privateigentums usw. und die darauf aufbauenden Rechtsbeziehungen nur unvollständig entwickelt waren, und daß damit auch der Staat nur nebenbei, nicht primär jener Garant des friedlichen Austauschs quasi außerhalb der Gesellschaft von Privatpersonen war.

Zunächst fällt auf, daß es in Athen gar kein Wort für ,Staat ${ }^{6}$ gibt; und ebenso mangelt es am Begriff der staatlichen Souveränität. Die mit dem Territorium Attika verbundenen Rechte lassen sich erschöpfend aufteilen auf die Rechte der einzelnen Athener und auf die Rechte der Athener als Kollektiv. In Verträgen mit anderen Poleis ist das Rechtssubjekt auf der athenischen Seite bezeichnet als hoi Athenaioi "die Athener"; der Staat existiert jedenfalls dem Namen nach nicht als besonderes Rechtssubjekt, z. B. als die Krone. Wenn jemand in Athen explizit die Souveränität ausübt, dann noch am ehesten die Athener insgesamt, d. h. die versammelte Masse der Vollbürger. Souveränität jenseits davon gibt es nicht, weil es keinen staatlichen Machtapparat jenseits der, im Zweifelsfall bewaffneten, Masse der Athener, der freien Athener gibt.

Heer und Flotte sind grob als Volksarmee zu beschreiben, mit von der Volksversammlung gewählten Kommandeuren. Polizei (ubrigens meistens Gemeindesklaven, wo also ,die Athener' Kollektiveigentümer sind) existiert nur zu bestimmten Wachaufgaben. Eine bürokratisch organisierte Verwaltung gibt es, im deutlichem Unterschied zum Imperium Romanum allenfalls in Ansätzen: die leitenden Beamten sind fast ausnahmslos gewählte Jahresbeamte (z. B. zur Verwaltung der öffentlichen Einkünfte und des Tempelschatzes oder der Marinearsenale), ausführende Arbeiten werden von Gemeindesklaven besorgt (z. B. im Archiv, in der Münze oder in der Vorform von Strafvollzug). Der Unterschied zum modernen Staat ist besonders auffallend bei der Rechtsprechung, die nicht ais besondere Gewalt organisiert ist: es 
gibt keine hauptberuflichen Richter und Staatsanwälte, sondern nach bloßer Vorbereitung durch die Jahresbeamten wird Recht gesprochen in Gerichtshöfen, die mit ausgelosten Bürgern in großer Zahl besetzt waren. Zunächst waren es ja dieselben Athener, die abwechselnd Gesetze verabschiedeten und auslegten. Sodann war zwar strikteste Bindung an den Gesetzestext vorgeschrieben, aber das schloß Lücken und Unklarheiten in den Gesetzen nicht aus: vielfach waren Tatbestand und Strafmaß äußerst ungenügend definiert. Die Folge war die Übernahme legislativer Funktionen durch die Gerichte bzw. vielfach Willkür - der Rechtsprechung fehlte ein entscheidendes Erfordernis, die Berechenbarkeit.

Der athenischen Polis ist also der Begriff des Staates im modernen Sinn nicht eigentlich angemessen. Vielmehr handelt es sich um Momente des modernen Staats, die sich bereits unter wesentlich anderen Verhältnissen entwickeln und die vom entwickelten modernen Staat her als Keimformen begriffen werden können. Diese einzelnen Momente haben teilweise bereits eine beachtliche Entwicklung gehabt (ähnlich wie auch das Geld und seine Formen als Handels- und Geldkapital). Aber sie haben sich nicht zu einer separaten Einheit über einer rein ökonomischen Sphäre und zu deren Garantie verselbständigt. In Athen gibt es nicht den über die Masse der Bürger verselbständigten Staat. Diese Bürger sind prinzipiell und primär politische Bürger, nicht auseinandergelegt also in Citoyens und Bourgeois. Wenn es eine dieser Scheidung entsprechende Trennung gibt, so wohl nur ansatzweise die im einzelnen Menschen, viel eher die zwischen verschiedenen Schichten der Bevölkerung. Einerseits die - im Vergleich zum Postulat voller politischer Gleichheit in der zeitgenössischen bürgerlichen Gesellschaft - privilegierten Polisbürger, ,die Athener. Andrerseits die in Gewerbe und in Waren- und Geldhandel tätigen ,Metöken', fest ansässige, freie Ausländer mit Sonderrechten (insbesondere der Rechts- und Prozeßfähigkeit), aber nur sehr beschränkten politischen Rechten (deren Basis das Recht auf Haus- und Grundbesitz war - selbst in der klassischen Zeit waren die athenischen Polisbürger in ihrer großen Mehrheit Grundbesitzer). Die für die entwickelte bürgerliche Gesellschaft charakteristische Scheidung von ökonomischei und politischer Sphäre erscheint hier anscheinend als Trennung von okonomischen und politischen Menschen. Die Grenzen sind allerdings in der Wirklichkeit keinswegs strikt eingehalten (wie auch nicht wenige Sklaven in Handel und Gewerbe tätig waren, teilweise mit erheblicher Selbständigkeit, und insoweit gewisse Rechte im Handelsrecht genossen; im übrigen tun sie die, notwendigen Werke (Aristoteles), d. h. die tagtägliche Kleinarbeit unterhalb und außerhalb der Sphäre des Warentauschs). Vielmehr geht ein dauernder Druck von der, ökonomischen ${ }^{6}$ Sphäre aus, dem durch politische Maßnahmen zu begegnen versucht wird. Wenn Sitte und direkte Verbote das Eindringen in den Bürgerstand erschwerten, so konnten doch in vielen Fällen allerlei Privilegien und Rechte gekauft werden; umgekehrt konnten Polisbürger die einträglichen Geschäfte durch Beauftragte erledigen lassen, z. B. durch Sklaven. Im übrigen waren sehr viele gerade der athenischen Bürger ,Banausen', als Taglöhner, Handwerker und auch Händler und Kaufleute tätig, von den zahlreichen Bauern einmal abgesehen; sie standen also mit einem Bein in der Sphäre des, ökonomischen“, banausischen Erwerbslebens. 
Man wird die Gesellschaft der Polis Athen also nur angemessen begreifen können, wenn man sie als eine Übergangsgesellschaft versteht, als eine Gesellschaft im Konflikt zwischen zwei grundsätzlich verschiedenen Formen der Vergesellschaftung. Einzelne Momente des Neuen, das erst in der modernen bürgerlichen Gesellschaft ganz zu sich kommt, sind hier bereits erkennbar entwickelt, wenngleich nicht so deutlich und selbständig wie im Römischen Reich. Das gilt besonders auch darum ging es in diesem Aufsatz - von Momenten des modernen, des bürgerlichen Staates, die sich hier gegen eine im wesentlichen noch andersartige Umwelt heraus. bilden. Die antike bürgerliche Gesellschaft steht also am Anfang eines langwierigen Übergangs- und Umwälzungsprozesses, der zur kapitalistischen Gesellschaft führt. Gerade die Langwierigkeit der Herausarbeitung solcher - für uns selbstverständlichen - Formen, wie der Person, des Vertrags usw., kann ein wenig darauf verweisen, wie umfassend und langwierig der Übergangsprozeß von der kapitalistischen zu einer kommunistischen Gesellschaft zu verstehen ist (weshalb auch der Begriff der Übergangsgesellschaft diesen Prozeß etwas verharmlost). Das dürfte überhaupt der Sinn historischer Untersuchungen sein: es geht nicht um ein objektivistisches Sammeln von antiquarischen Wissensstücken, sondern darum, das Bestehende und seine scheinbar selbstverständlichsten Existenz- und Bewußtseinsformen als gesellschafflich Produziertes zu begreifen. Es geht um das Verständnis der geschichtlichen Herkunft der eigenen Gesellschaft und aller in ihr hervorgebrachten Formen, die als Formen ihr Gewordensein verhüllen, bis hin zu den scheinbar festesten Kategorien, wie etwa dem Bewußtsein der eigenen subjektiven Identität und der Identität des Objektes oder dem Begriff des Gesetzes, der Kausalität usw. (42). Denn nur eine derart umfassende Auffassung der gesellschaftlichen Produktion - die allein in der kapitalistischen Gesellschaft zerfällt in Produktion im engeren Sinn, als Anhängsel der Mehrwertproduktion, und in Produktion im weiteren Sinn, als notdürftig von Familie, Staat usw. erledigter - kann die Aufgabe von Utbergangsgesellschaften heute sichtbar machen. In den Gesellschaften im Übergangsprozeß zum Kommunismus werden alle Formen der bürgerlichen Gesellschaften ,aufzuheben' sein, auch solche wie die der Person, des Vertrags usw. Aber selbst wenn man dieser Feststellung sogleich hinzufügt: aber keineswegs auf einen Schlag, sondern in einem langwierigen Prozeß, so ist damit doch immer noch wenig mehr als nichts gesagt; ja diese Feststellung kann gefährlich verkürzend sein. Denn ,Aufhebung ${ }^{6}$ ist Bewahrung und Vernichtung; aber muß dies, wie das einzige Wort nahelegt, in einem geschehen? Und betrifft es alle Formen in gleichem Maße? Ist vielleicht bei einzelnen mehr an Erhaltung zu denken, bei anderen mehr an Úberwindung? Wie ist es etwa bei der Form der Person und ihrer Freiheit und Gleichheit vor dem Gesetz? Gehen diese Kategorien einfach in ihrer Funktion beim Austausch und bei der Verhïllung der Ungleichheit in der Sphäre der materiellen Produktion auf? Oder sind sie nicht zugleich weit über die bürgerliche Gesellschaft hinausweisende Grund- 
formen, die als politische Teilnahmerechte (43) den Widerstandskampf der Arbeiterklasse legitimieren, ja Grundrechte der einzelnen Gesellschaftsmitglieder auch in der Übergangsgesellschaft antizipieren, welche ohne Gefahr des Rückfalls in Formen direkter Herrschaft als Errungenschaften nicht aufgegeben werden dürfen? Sind diese Bewußtseinsformen und Rechte in gewissem Sinne vielleicht unaufgebbare „Errungenschaften" der bürgerlichen Gesellschaft, errungen oft erst durch die organisierten Arbeiter? Andererseits: sind es nicht gerade die im Begriff der Person zusammenzufassenden typisch ,bürgerlichen 'Verhaltensweisen, die jede tiefergreifende Überwindung der bürgerlichen Gesellschaft behindern oder unmöglich machen? Sind es nicht gerade diese verinnerlichten Orientierungen der einzelnen auf Einzelverhalten, die in manchen Übergangsgesellschaften nicht ernstlich angetastet sind und aus denen daher die bürgerliche Gesellschaft erneut aufzuerstehen sucht?

Mit Sicherheit läßt sich das Oszillieren zwischen diesen beiden Polen der ,Aufhebung ${ }^{6}$ bürgerlicher Formen nicht allein durch Analyse und Kritik auflösen. Mochte Marx vor 100 Jahren jeden Versuch zur positiven Konstruktion einer sozialistischen Gesellschaft als utopisch verwerfen; inzwischen steht die Konstruktion sozialistischer Übergangsgesellschaften so oder so auf der Tagesordnung, einer Konstruktion, die positiv bis in die Details die Aufgaben gesellschaftlicher Produktion auf industrieller Stufe klären und praktisch bewältigen muß, wenn diese Gesellschaft nicht untergehen oder unterliegen will. Und diese Aufgabe der Aufhebung der bürgerlichen Gesellschaft im umfassenden und im detaillierten Sinn stellt sich nicht nur in den heutigen Übergangsgesellschaften, sondern ist auch für die Linke in den kapitalistischen Gesellschaften keine utopische Aufgabe mehr. Das Vertrauen in die Fähigkeit der Massen zur spontanen Selbstorganisation im Augenblick der Revolution ist nur eine Verkennung dieser schwierigen Aufgabe.

43 Etwa wenn das Recht der Gleichheit aller Staatsbürger auch als Forderung auf gleiches Wahlrecht verstanden wird; eine Forderung, die vom Proletariat gegen die politische Vorherrschaft der Bourgeoisie durch das Zensuswahlrecht gewendet und erst in unserem Jahrhundert weitgehend durchgesetzt wurde (in Portugal erst kürzlich, in Südafrika nur für die weißen Arbeiter). 